is the energetic action of the Central Institution of the City and Guilds of London, \&c. I frankly admit that I am rejoiced to hear it, and will thank God, therefore, though not in German, as is the way of superior people.

Some information on other points is, however, desirable to explain apparent anomalies.

For instance, why are we compelled, in Dr. Armstrong's phrase, to "expatriate our most capable students by Royal Commission?"

Why are the German laboratories so full of English and American students that names have to be taken in rotation, and in some cases instructions have had to be issued that preference is to be given to native students, and the number of foreigners limited?

Dr. Armstrong tells us that the education in "quite a number of our schools" is "even superior to that given in Germany." This is good news, and should soon attract-or perhaps it already has attracted-many students from Germany.

But, seriously, can one of our schools be named which, for building equipment and number of staff, is on a level with the best German examples?

Does Dr. Armstrong really mean to defend the use to which the education funds have been put by the counties and boroughs ? Does he mean to say that the right persons have been charged with the duty of carrying on technical education? Does he think that a technical faculty could not be founded, or would have no value? Does he maintain that the sums spent-vast in the aggregate-have not been frittered away in teaching fragmentary science, \&c., to people who do not need it ?

If he says yes, then, regretting to differ, I must still main. tain that while teaching as a rule has been, and is, too academical, the money would have been better employed had it been handed over to institutions such as his and Prof. Meldola's, for the purpose of founding technical faculties, for the erection of laboratories, and for the provision of more teachers in them, rather than in founding a host of places for teaching smatterings of science to artisans.

It seems to me to be a repetition of the errors of fifty years back. The originators of the "institutes" and " polytechnics" of the middle of the century made mistakes in a small way, and we are repeating them on a vast scale.

My critic says that this is not so, and that such a view gives an " entirely false impression."

I can only say that I heartily hope that I am wrong, for since no one has felt the opprobrium of the position more, no one will rejoice more if Dr. Armstrong's view is right.

In conclusion, may I add a word on Mr. Pope's letter in your issue of February 23. My withers are unwrung thereby, yet I can sympathise with those manufacturers who did refuse specimens. But there is another aspect of the question, than the easy acquisition of fine objects for the lecture table or iaboratory museums for Mr. Pope, and those similarly placed, to consider, viz. the grave responsibility that a teacher incurs when he even seems to advertise the goods of any particular manufacturer. That is why such goods should always be purchased, and thus all obligation avoided.

R. J. FRISWELL.

March I I

IN the current number of the Berichte, the following advertisement appears :- "Eine grosse Anilinfarbenfabrik sucht für das theoretische Laboratorium gut geschulte Chemiker. Praxis nicht erforderlich." Is not this a striking indication of the nature of the material from which the so-called "German technologist" is evolved, and of the methods by which Germany has attained so great a success in chemical industry? William A. DAVIS.

Central Technical College, Exhibition Road, March Ir.

\section{Sunspots and Weather.}

I HAVE thought the following may be worth attention.

Count the number of warm months, and the number of wet months, at Greenwich, in each year, since $184 \mathrm{I}$ (i.e. months above average in either case). Select the values in each of the five-year groups having a sunspot maximum year central; and the same with minimum.

This gives twenty-five numbers of warm months to be compared with twenty-five numbers of wet months, for sunspot max. groups; and like numbers for min. groups.

$$
\text { NO. I 533, VOL. 59] }
$$

These may be compared by means of dots; using the ordinates for warm months, and the abscisse for wet months. The average of warm months is six, that of wet months about five.

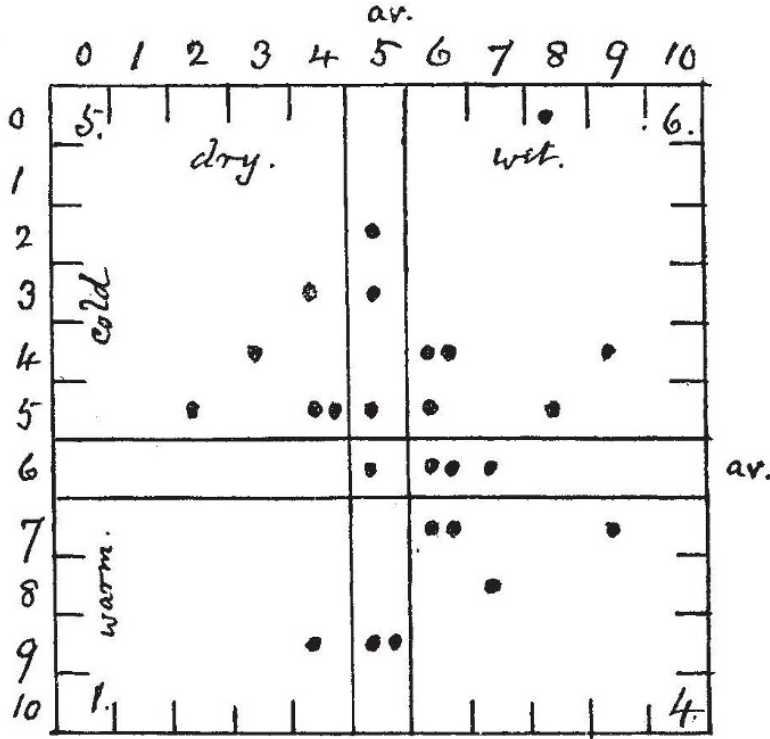

Minimum sunspot groups.

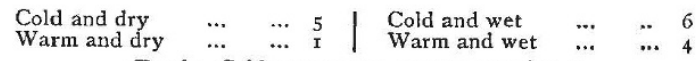

Totals-Cold, 14 ; warm, 7 ; wet, 13 ; dry, 6.

Some interesting contrasts come out.

Thus, in the minimum groups, there is only one year both warm and dry (I868); in the max. groups, eight. In the latter, only two years both wet and cold; in the former, six.

ar.

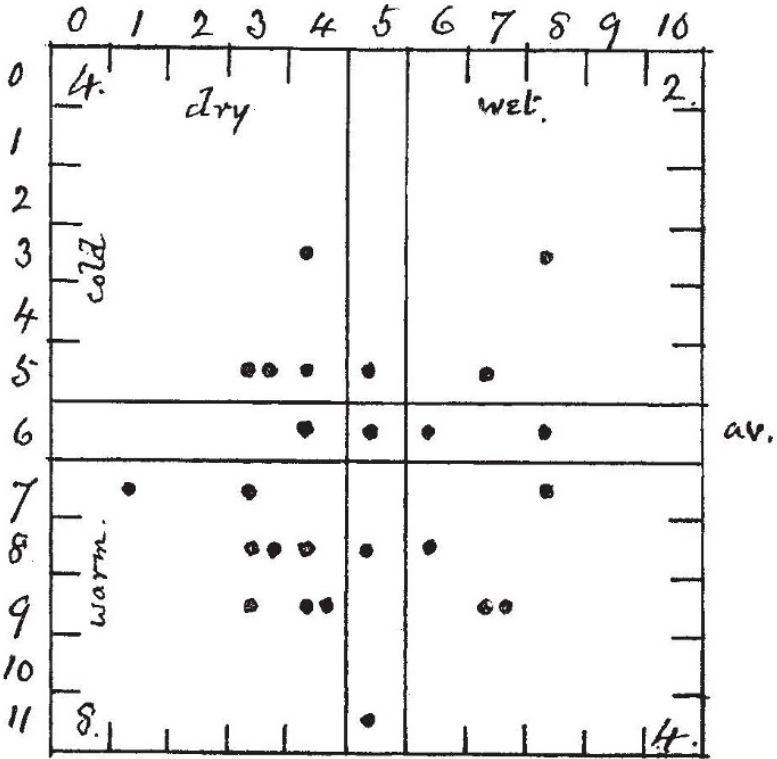

Maximum sunspot groups.

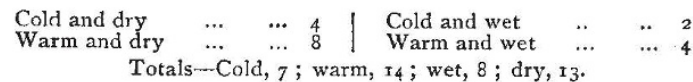

Compare, too, the total, cold, warm, wet, and dry, as at foot of diagram.
Alex. B. MacDowall. 